Universidade Tecnológica Federal do Paraná - UTFPR

Campus Ponta Grossa - Paraná - Brasil

ISSN: $1981-3686$ / v. 2, n. 2: p. 96-102, 2008
Revista Brasileira deTecnologia

Agroindustrial

\title{
DETERMINAÇÃO DE CIANETO TOTAL NAS FARINHAS DE MANDIOCA DO GRUPO SECA E D’ÁGUA COMERCIALIZADAS NA CIDADE DE BELÉM-PA
}

\section{TOTAL CYANIDE DETERMINATION FROM CASSAVA FLOUR OF DRY AND WATER GROUPS TRADED IN THE CITY OF BELÉM-PA.}

\author{
Renan Campos Chisté ${ }^{1}$, Kelly de Oliveira Cohen ${ }^{2}$ \\ ${ }^{1}$ Universidade Estadual de Campinas - UNICAMP - Campinas-SP - Brasil \\ ${ }^{2}$ Embrapa Recursos Genéticos e Biotecnologia - CENARGEN - Brasília-DF - Brasil \\ renanchiste@gmail.com
}

\section{Resumo}

O objetivo desse trabalho foi determinar a concentração de cianeto total presente nas farinhas de mandioca do grupo seca e d'água comercializadas na cidade de Belém, PA, sabendo que os efeitos tóxicos causados pela liberação de cianeto podem ser agudos ou crônicos. Após realização das análises verificou-se que as farinhas de mandioca apresentaram baixa concentração de cianeto total, variando de 7,68 a 20,57 mg HCN/Kg nas farinhas do grupo seca e de 3,57 a 12,36mg HCN/Kg na farinha do grupo d'água.

Palavras-chave: Manihot sculenta, farinha, ácido cianídrico, intoxicação.

\section{Introdução}

A mandioca (Manihot esculenta Crantz) é originária do Brasil, região amazônica, fronteiriça com a Venezuela e constitui-se em alimento energético para mais de 400 milhões de pessoas no mundo, sobretudo nos países em desenvolvimento, onde é cultivada por pequenos agricultores, em áreas reduzidas e com baixa produtividade. Em área cultivada, a mandioca ocupa o $7^{\circ}$ lugar no mundo e o $4^{\circ}$ nos trópicos (CAGNON et al., 2002).

A maioria da produção brasileira de mandioca é destinada à produção de farinha de mandioca. Ao contrário da produção de fécula, da mandioca de mesa e de raspas ou pellets, a 
farinha de mandioca não conta com mercados de exportação significativos. O Brasil é o único país da América Latina que consome farinha em quantidades expressivas (VILPOUX, 2003).

A farinha de mesa é o derivado da mandioca mais amplamente difundido no país, sendo consumida de diferentes maneiras em todas as regiões. De acordo com CARDOSO et al. (2001), os principais produtos das raízes de mandioca, no nordeste paraense, são as farinhas d'água, seca e mista (mistura da massa ralada e fermentada), que podem ser branca ou amarela. Segundo a Portaria

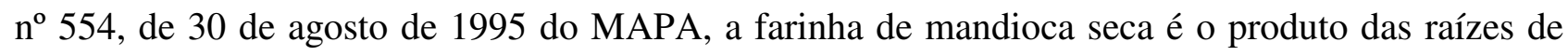
mandioca sadias, devidamente limpas, descascadas, trituradas (moídas), prensadas, desmembradas, secas à temperatura moderada ou alta e novamente peneirada ou não, podendo ser beneficiada. $\mathrm{E}$ a farinha de mandioca d'água é o produto das raízes de mandioca sadias, devidamente limpas, maceradas, descascadas, trituradas (moídas), prensadas, desmembradas, peneiradas, secas à temperatura moderada, podendo novamente ser peneiradas ou não.

A mandioca acumula dois glicosídeos cianogênicos nas raízes e folhas, linamarina e lotaustralina, em proporções de aproximadamente 93:7. Esses dois glicosídeos são capazes de gerar ácido cianídrico $(\mathrm{HCN})$, desde que ocorra hidrólise. Quando o tecido vegetal é dilacerado, a linamarina é hidrolisada enzimaticamente por $\beta$-glicosidase (linamarase), a qual é separada do glicosídeo no tecido intacto, por ser localizada em lugar distinto da célula. A clivagem produz glicose e $\alpha$-hidroxinitrilas. Esta última quando catalisada por uma hidroxinitrila liase, transforma-se espontaneamente em HCN e nas cetonas correspondentes (CEREDA, 2003). Embora essa reação possa não ocorrer na planta, enzimas presentes no trato digestivo dos animais e seres humanos possuem a capacidade de efetivá-la, podendo advir sintomas de intoxicação dependendo da quantidade e tipo de alimento ingerido (CAGNON et al., 2002).

Em função do teor de $\mathrm{HCN}$ apresentado, classificam-se as mandiocas quanto a toxicidade em mansas: menos de $50 \mathrm{mg} \mathrm{HCN/Kg}$ de raiz fresca sem casca; moderadamente venenosa: 50 a 100 $\mathrm{mg} \mathrm{HCN} / \mathrm{Kg}$ de raiz fresca sem casca; venenosa ou brava: acima de $100 \mathrm{mg} \mathrm{HCN} / \mathrm{Kg}$ de raiz fresca sem casca. O conhecimento da toxicidade da planta limita o seu emprego, tanto na alimentação humana como na nutrição animal. As técnicas de processamento industrial para diminuição do princípio tóxico baseiam-se na dissolução em água ou na volatilização, envolvendo processos como a maceração, embebição em água, fervura, torrefação ou fermentação das raízes de mandioca, ou ainda, a combinação desses processos (CAGNON et al., 2002).

Sendo a farinha de mandioca (seca ou d'água) a principal fonte de carboidrato para uma significativa parcela da população de menor poder econômico no estado do Pará, com consumo per capita de $34 \mathrm{~kg}$ na região metropolitana de Belém (CARDOSO et al., 2001), este trabalho tem por finalidade determinar a concentração de cianeto total presente nas farinhas de mandioca do grupo 
seca e d'água comercializadas nas principais feiras e supermercados da cidade de Belém, PA, avaliando se o processo de produção, das casas de farinha fornecedoras, foi realizado de maneira efetiva na detoxificação do produto.

\section{Material e Métodos}

\subsection{Amostras}

Foram coletas 10 (dez) amostras de farinha de mandioca do grupo seca e 10 (dez) amostras de farinha de mandioca do grupo d'água nas principais feiras e supermercados da cidade de Belém, PA.

\subsection{Quantificação de cianeto total}

Para a determinação de cianeto total utilizou-se a metodologia descrita por Cooke (1978) e, posteriormente adaptada por Essers et al. (1993), na qual ocorre oxidação do cianeto $\left(\mathrm{CN}^{-}\right)$à haleto de cianogênio cloroamina $\mathrm{T}$ ou $\mathrm{N}$-clorosuccinimida. Este composto reage com ácido isonicotínico para produzir um dialdeído que acopla com aminas ou compostos com o grupamento metileno como ácido dimetilbarbitúrico para formar um complexo colorido e posterior leitura em espectrofotômetro. A metodologia utilizada encontra-se resumida na Tabela 1.

Tabela 1. Metodologia de análise de cianeto total na farinha de mandioca.

\begin{tabular}{|c|c|c|c|c|c|c|}
\hline Buffer & Amostra & Linamarase & $\mathrm{NaOH} 0,2 \mathrm{M}$ & Buffer & Cloramina $\mathrm{T}$ & Reagente de cor \\
\hline $\mathrm{pH} 7,0$ & (extrato) & $\left(15^{\prime} / 30^{\circ} \mathrm{C}\right)$ & ( $5^{\prime}$ repouso) & $\mathrm{pH} 6,0$ & (agitar, gelo $5^{\prime}$ ) & (agitar, repouso $10^{\prime}$ ) \\
\hline
\end{tabular}

Todas as análises foram realizadas em quadruplicata.

A leitura de absorbância foi realizada em espectrofotômetro da marca Varian, Cary 50 Bio visível a $605 \mathrm{~nm}$, com concentrações variando de 0,013 a 2,708 $\mu \mathrm{g}$ HCN.0,1 mL $\mathrm{m}^{-1}$, totalizando 11 pontos para a construção da curva padrão. 


\section{Resultados e Discussão}

De acordo com a tabela 1, a dosagem de cianeto total presente nas farinhas de mandioca do grupo seca e d'água comercializadas nas principais feiras e supermercados da cidade de Belém-PA apresentou valores baixos em sua concentração, variando de 7,54 a 20,78 mg HCN/Kg na farinha seca e de 3,57 a 12,36 mg HCN/Kg na farinha d'água, apresentando pequena variação estatística $(\mathrm{p}<0,05)$ entre os produtos de diferentes procedências.

Tabela 1 - Dosagem de cianeto total nas farinhas de mandioca do grupo seca e d'água comercializadas na cidade de Belém-PA.

\begin{tabular}{cc|cc}
\hline \hline $\begin{array}{c}\text { Farinha } \\
\text { Seca }\end{array}$ & $\begin{array}{c}\text { Cianeto Total } \\
(\mathrm{mg} \text { HCN/Kg })\end{array}$ & $\begin{array}{c}\text { Farinha } \\
\text { D'água }\end{array}$ & $\begin{array}{c}\text { Cianeto Total } \\
(\mathrm{mg} \mathrm{HCN} / \mathrm{Kg})\end{array}$ \\
\hline \hline 1 & ${ }^{\mathrm{a}} 7,54 \pm 0,30$ & 1 & ${ }^{\mathrm{a}} 4,60 \pm 0,33$ \\
2 & ${ }^{\mathrm{b}} 10,19 \pm 0,44$ & 2 & ${ }^{\mathrm{a}} 5,03 \pm 0,28$ \\
3 & ${ }^{\mathrm{c}} 8,81 \pm 0,11$ & 3 & ${ }^{\mathrm{b}} 3,57 \pm 0,24$ \\
4 & ${ }^{\mathrm{d}} 12,19 \pm 0,31$ & 4 & ${ }^{\mathrm{c}} 8,55 \pm 0,32$ \\
5 & ${ }^{\mathrm{d}} 12,06 \pm 0,22$ & 5 & ${ }^{\mathrm{d}} 9,40 \pm 0,07$ \\
6 & ${ }^{\mathrm{e}} 20,78 \pm 0,42$ & 6 & ${ }^{\mathrm{e}} 5,82 \pm 0,32$ \\
7 & ${ }^{\mathrm{d}} 12,51 \pm 0,50$ & 7 & ${ }^{\mathrm{ae}} 5,27 \pm 0,26$ \\
8 & ${ }^{\mathrm{d}} 11,52 \pm 0,45$ & 8 & ${ }^{\mathrm{ae}} 5,31 \pm 0,19$ \\
9 & ${ }^{\mathrm{f}} 14,58 \pm 0,74$ & 9 & ${ }^{\mathrm{c}} 8,34 \pm 0,16$ \\
10 & ${ }^{\mathrm{b}} 10,21 \pm 0,39$ & 10 & ${ }^{\mathrm{f}} 12,36 \pm 0,33$ \\
\hline
\end{tabular}

Médias com letras iguais, em uma mesma coluna, não diferem significativamente entre si (Teste de Tukey a 5\% de significância). Média das amostras obtidas em quadruplicata.

De acordo com Cereda (2003), o processo de fabricação da farinha de mandioca, que consiste basicamente em ralar, prensar, esfarelar e secar (torrefação), sob o aspecto da eliminação do cianeto, é efetivo, porque ao ralar coloca-se em contato enzima e substrato nas melhores condições de reação, pH entre 5,5 e 6,0 (pH natural da raiz) e temperatura ambiente. Após as condições ótimas de hidrólise, a prensagem carreia a linamarina que possa ter restado íntegra e a acetona cianoidrina, ambas solúveis em água. Por fim o cianeto livre na forma de HCN é eliminado pelo aquecimento do produto úmido, em forno aberto. Resíduos de cianeto não eliminados no processo podem vir de adaptações do processo, ou da falta de equipamentos mais eficientes, sendo 
que o processamento demorado, ou etapas que são cortadas, levam à condições desfavoráveis de detoxificação. Tais condições como falta de estrutura, processamento artesanal, demora no processamento completo da raiz após a chegada nas farinheiras, são comuns nas casas de farinha pelo interior do Pará. Chisté et al. (2006) observaram que nas Casas de Farinha o processo sofre interrupções, ocorrendo de a massa de mandioca triturada ficar exposta de um dia para o outro à temperatura ambiente, que na região norte gira em torno dos $25{ }^{\circ} \mathrm{C}$ aos $35{ }^{\circ} \mathrm{C}$, ocasionando, naturalmente, a sua fermentação, aumentando, portanto, a acidez do produto.

Os teores de cianeto total apresentaram valores menores na farinha de mandioca d'água devido ao processo adicional de fermentação ao qual a raiz é submetida, etapa característica do processamento que a diferencia da farinha de mandioca do grupo seca. De acordo com Onabowale (1992), o ácido cianídrico da mandioca pode ser detoxificado por fermentação, hidrólise ácida ou ambos. A hidrólise ácida foi mais efetiva, removendo $98 \%$ do total de cianeto das raízes de mandioca, enquanto a fermentação combinada com hidrólise ácida, e a fermentação sozinha, reduziram o teor de cianeto em 95 e $87,84 \%$, respectivamente.

De fato, o processo de fabricação da farinha de mandioca, que leva à produção da farinha seca e d'água, pode dar origem a produtos diferenciados com relação aos teores de cianeto em dependência de alguns fatores, como: a forma como o processo ocorre, se artesanal ou mecanizado; tipo de cultivar; idade da planta; tipo de solo; entre outros. Todos esses fatores podem originar plantas com diferentes concentrações de ácido cianídrico. No entanto, uma evidência para essas diferenças está no fato de que as raízes usadas para a produção de farinha de mandioca são raízes com alto teor de ácido cianídrico, isto é, são usadas raízes classificadas como mandiocas bravas, as quais gerarão, conseqüentemente, produtos com valores elevados de ácido cianídrico, caso o processo de detoxificação durante o processamento não seja eficaz. Dufour (1988) cita a existência de raízes de mandioca com altos teores de ácido cianídrico ao analisar etnovariedades de mandiocas da Amazônia, constatando valores variando de 311 a 508 mg HCN. $\mathrm{kg}^{-1}$ de raiz fresca, com média de $454 \mathrm{mg} \cdot \mathrm{kg}^{-1}$, consideradas como altamente tóxicas.

Neste trabalho, foram quantificados os teores de cianeto total presentes em farinha de mandioca, que é um produto da industrialização da mandioca muito usado no norte do Brasil. Assim sendo, quantificar os teores de cianeto previamente em raízes de mandioca torna-se muito importante no caso de posterior ingestão de produtos crus ou mal processados, pois a linamarina remanescente, não hidrolizada, que sobra desse processamento das raízes, poderá causar problemas de saúde quando esse residual for hidrolizado no corpo humano ou animal, liberando cianeto livre (HCN) (TEWE, 1984; BALAGOPALAN et al., 1988; CAGNON et al., 2002).

Após estudos da determinação do potencial de intoxicação em ratos, de linamarina extraída 
de mandioca, feita por Cereda \& Lopes (2003), os autores chegaram à conclusão de que a DL50 (dose letal para $50 \%$ de ocorrência) oral de linamarina extraída foi $324,86 \pm 1,5 \mathrm{mg} / \mathrm{kg} / \mathrm{peso}$, correspondendo a $35,35 \mathrm{mg}$ de $\mathrm{HCN} / \mathrm{kg}$ peso. A DL50 aceita pela OMS é de $10 \mathrm{mg} / \mathrm{kg}$ de peso, menor que a estabelecida até agora. No presente estudo, a amostra 6 de farinha seca apresentou o maior valor de cianeto total $\left(20,78 \mathrm{mg} \mathrm{HCN} \cdot \mathrm{kg}^{-1}\right)$ e a amostra 10 da farinha d'água apresentou o maior valor (12,36 mg HCN. $\mathrm{kg}^{-1}$ ), portanto, com base nesses dados, um indivíduo adulto de $70 \mathrm{Kg}$ deveria ingerir na alimentação aproximadamente $33 \mathrm{~kg}$ de farinha seca e $57 \mathrm{~kg}$ de farinha d'água para que a $\mathrm{DL}_{50}$ seja alcançada, levando em consideração o limite aceito atualmente pela OMS. Obviamente nenhum consumidor irá ingerir numa única refeição tal quantia do produto. Confirmaram-se as informações da literatura de que a linamarina não é cumulativa e de que quando a DL50 não é alcançada, os animais se recuperam. De acordo com Cereda (2003), abaixo da dose letal existe um mecanismo de detoxificação na qual o cianeto é em transformado em tiocianato, em presença de enzima rodanase e cisteína, um aminoácido doador de enxofre. O tiocianato formado não é mais tóxico e é eliminado pela urina. Por essa razão, uma forma de saber se a linamarina esteve presente na alimentação e foi metabolizada, é a detecção e dosagem de tiocianato na urina.

\title{
4. Conclusão
}

As farinhas de mandioca do grupo seca e d'água comercializadas nas principais feiras e supermercados da cidade de Belém-PA, possuem valores de dosagem do cianeto total em concentrações baixas, não sendo suficiente para causar intoxicação em consumidores freqüentes do produto.

\begin{abstract}
The aim of this work was to determine the concentration of total cyanide in cassava flour of dry and water group traded in the city of Belém, PA, knowing that the toxic effects caused by the release of cyanide might be acute or chronic. After accomplish the analyses was verified that the cassava flour presented low concentration of total cianeto, that varies from 7,68 to $20,57 \mathrm{mg} \mathrm{HCN} / \mathrm{Kg}$ in flour of the dry group flour and from 3,57 to $12,36 \mathrm{mg} \mathrm{HCN} / \mathrm{Kg}$ in the water group flour.
\end{abstract}

Keywords: Manihot sculenta, flour, cyanidric acid, intoxication.

\section{Referências}

BALAGOPALAN, C.; PADMAJA, G.; NANDA, S.; MORTHY, S. Cassava in food. Feed and Industry. CRCPress, 
Boca Raton, FL.,1988.

CAGNON, J. R.; CEREDA, M. P.; PANTAROTTO, S. In Cd-rom. Série: Cultura de tuberosas amiláceas latinoamericanas. Vol.2 - Cultura de tuberosas amiláceas latino-americanas. Fundação Cargill. Ago/2002.

CARDOSO, E.M.R., MÜLlER, A.A., SANTOS, A.I.M., HOMMA, A.K.O., ALVES, R.N.B. Processamento e Comercialização de Produtos Derivados de Mandioca no Nordeste Paraense. Embrapa Amazônia Oriental. Documentos nº102 - 28p. Belém-PA. Jun/2001.

CEREDA, M. P.; Processamento da Mandioca como mecanismo de detoxificação. In Cd-rom. Série: Cultura de tuberosas amiláceas latino-americanas. Vol.3, cap.3 - Cultura de tuberosas amiláceas latino-americanas. Fundação Cargill. 2003.

CEREDA, Marney Pascoli; LOPES, Ana Maria. In Cd-rom. Determinação do potencial de intoxicação em ratos, de linamarina extraída de mandioca. Anais do V SLACA, Campinas-SP, 2003.

CHISTÉ, R.C.; COHEN, K.O.; MATHIAS, E.A.; RAMOA JUNIOR, A.G.A.; Qualidade da farinha de mandioca do grupo seca. Ciênc. Tecnol. Aliment., 26(4): 861-864, 2006.

COOKE, R.D.; “An Enzymatic Assay for the Total Cyanide Content of Cassava (Manihot esculenta Crantz)” J.Sci. Food Agric., 29, 345-352, 1978.

DUFOUR, D.L.; Effectiveness of cassava detoxification techniques used by indigenous peoples in Northwest Amazonia. Interciencia, Caracas, v.14, n.2. p.86,91, 1988.

ESSERS, A.J.A.; BOSVELD, M.; GRIFT, R. M.V.D.; VORAGEN, A. G. J.; Assay for the cyanogens content in cassava products. (Preliminary Version, December, 1993). Department of food Science, Wageningen. Agricultural University, Netherlands. 9p, 1993.

MAPA - Ministério da Agricultura, Pecuária e Abastecimento. Portaria no 554, de 30 de agosto de 1995.

ONABOWALE, S.O; Constrains and projections for processing and utilization of cassava. In: HAHN, S.K.; REYNOLDS, L.; EGBUNIKE, G.N.; Cassava as livestock in Africa. Workshop on the potential utilization of cassava as livestock feed in Africa, Ibadan, 1988. Proceedings: Ibadan, International Institute of Tropical Agriculture/ILCA/University of Ibadan, p.112-118, 1992.

TEWE, O. Cyanogenic glycoside, protein interaction in cassava peel based rations. Nutr. Rep. Int. v. 30, p. 425-431, 1984.

VILPOUX, Olivier. Produção de Farinha d'água no Maranhão. In Cd-rom. Série: Cultura de tuberosas amiláceas latinoamericanas. Vol.3 Cap.21. Cultura de tuberosas amiláceas latino-americanas. Fundação Cargill. 2003.

\section{AGRADECIMENTOS}

Ao Fundo Estadual de Ciência e Tecnologia (FUNTEC) / Secretaria Executiva de Ciência, Tecnologia e Meio Ambiente (SECTAM), pelo apoio financeiro.

Nome completo: Renan Campos Chisté.

Filiação institucional: Universidade Estadual de Campinas - UNICAMP.

Departamento: Departamento de Ciência de Alimentos - DCA.

Função ou cargo ocupado: Doutorando em Ciência de Alimentos.

Endereço completo para correspondência: Universidade Estadual de Campinas, Faculdade de Engenharia de Alimentos, Departamento de Ciências de Alimentos. FEA/DCA/ Caixa Postal 6121.

Telefone para contato: (19) 35212159

e-mail: renanchiste@gmail.com 